\title{
Evaluation of collateral blood flow by myocardial contrast enhanced echocardiography
}

\author{
PETR WIDIMSKY, JAN H CORNEL, FOLKERT J TEN CATE \\ From the Thoraxcenter, Erasmus University, Rotterdam, The Netherlands
}

SUMMARY Contrast enhanced cross sectional echocardiography is a new method for the real-time evaluation of regional myocardial perfusion. Two patients with a history of anteroseptal myocardial infarction and echocardiographically detected septal dyskinesia were examined by this new method. The first patient had two severe stenoses of the left anterior descending coronary artery and normal echocontrast opacification of the interventricular septum caused by collaterals from the right coronary artery. The second patient had good patency of left anterior descending coronary artery and no septal opacification. Thus contrast enhanced cross sectional echocardiography can be used to assess the importance of collateral blood flow in the myocardium.

Contrast enhanced cross sectional echocardiography is a new method of assessing perfusion within the left ventricular myocardium. ${ }^{2}$ In experimental myocardial infarction there was no echocontrast opacification of the necrotic area after reperfusion, whereas in the marginal viable areas echocontrast slowly reappeared. ${ }^{2}$ The size of echocardiographically assessed perfusion defect after reperfusion of the epicardial coronary artery correlated with the anatomical infarct size. During the past two years the first reports on the use of contrast enhanced cross sectional echocardiography of the human myocardium have appeared. ${ }^{34}$ The present two case reports show the potential of this method for the evaluation of preserved perfusion in dyskinetic myocardium (and so probably of myocardial viability) and for the visualisation of collateral blood flow.

\section{Patients and methods}

\section{CASE 1}

A 66 year old woman had an anteroseptal myocardial infarction with subsequent left bundle branch block in 1984. Since then she had had progressive angina pectoris (New York Heart Association class III) and mild intermittent congestive heart failure. She had a

Requests for reprints to Dr Folkert J Ten Cate, Cardiovascular Research 23rd floor, Erasmus University Rotterdam, PO Box 1738, 3000 DR Rotterdam, The Netherlands.

Accepted for publication 17 June 1987 complete cardiological evaluation including coronary arteriography in October 1986. The examination showed a severe double stenosis $>90 \%$ of the proximal left anterior descending coronary artery with clinically insignificant lesions $(<50 \%)$ in left circumflex and right coronary arteries. There were collaterals from the right coronary artery to the distal left anterior descending coronary artery. A dilated and diffusely hypokinetic left ventricle with an ejection fraction of $15 \%$ was shown by left ventriculography. Myocardial contrast enhanced cross sectional echocardiography was performed immediately after coronary arteriography. Sonicated iopamidol $(4 \mathrm{ml})^{5}$ was injected into the left main coronary artery and an echocardiographic apical four chamber view was recorded. There was considerable opacification of the lateral wall but no opacification of the dyskinetic septum and akinetic apex. (In a group of eight patients with normal coronary arteriograms we found in the apical four chamber view that the septum and apex were supplied from the left coronary artery.) During the subsequent right coronary injection there was considerable contrast enhancement of the septum (fig 1). Computer analysis of the time-intensity curve of myocardial echocontrast showed a longer contrast disappearance rate in the mid-ventricular level of the septum than in the lateral wall.

CASE 2

The second patient, a 61 year old man, showed the opposite pattern. A transmural anteroseptal myo- 


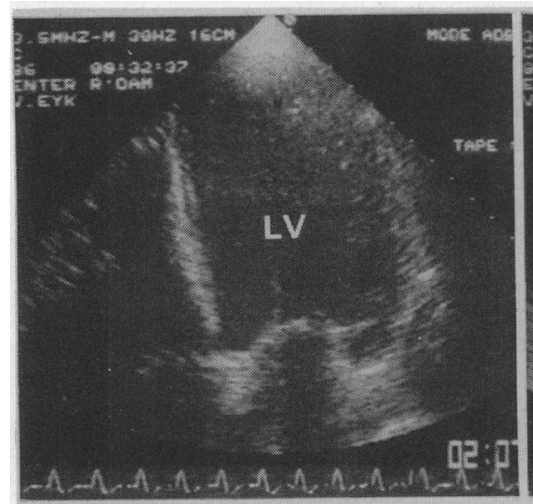

Baseline

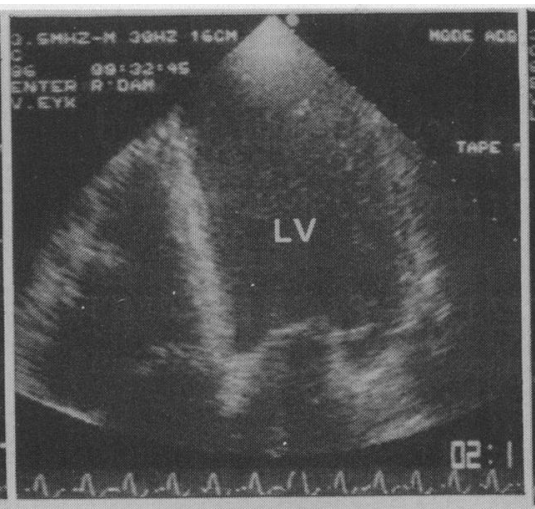

RCA injection

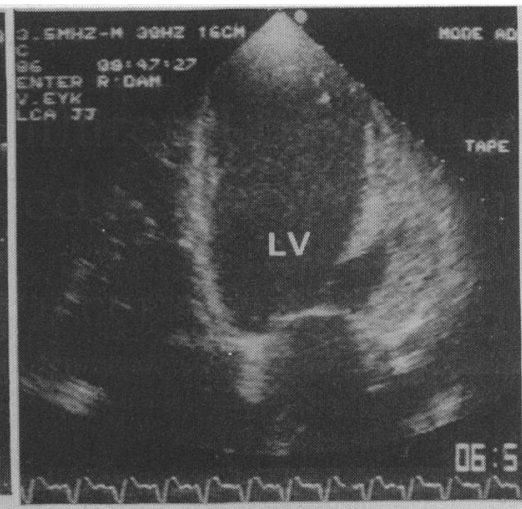

LCA injection

Fig 1 Opacification of the interventricular septum by collaterals from the right coronary artery. Left: baseline apical four chamber view; middle: opacification of the whole septum after injection of the right coronary artery; right: opacification of the lateral wall and septal perfusion defect after injection of the left coronary artery. LCA, left coronary artery; RCA, right coronary artery; $L V$, left ventricle.

cardial infarction in February 1986 was followed by a successful coronary angioplasty of a severe stenosis of the proximal left anterior descending coronary artery in April. Control coronary arteriography was performed in October 1986, followed by myocardial contrast enhanced cross sectional echocardiography. Only clinically unimportant lesions $(<50 \%)$ were seen in the coronary arteries, and there was good patency of the left anterior descending coronary artery. However, the branching of this artery was not visible. Left ventriculography showed apical dyskinesia with anteroseptal hypokinesia and ejection fraction of $26 \%$. Cross sectional echocardiography showed septal akinesia. Contrast enhanced cross sectional echocardiography of the myocardium in the apical four chamber view showed contrast opacification of the normal lateral wall with no visible contrast in the apex and septum. Nor did injection of echocontrast into the right coronary artery show any septal opacification. Computer
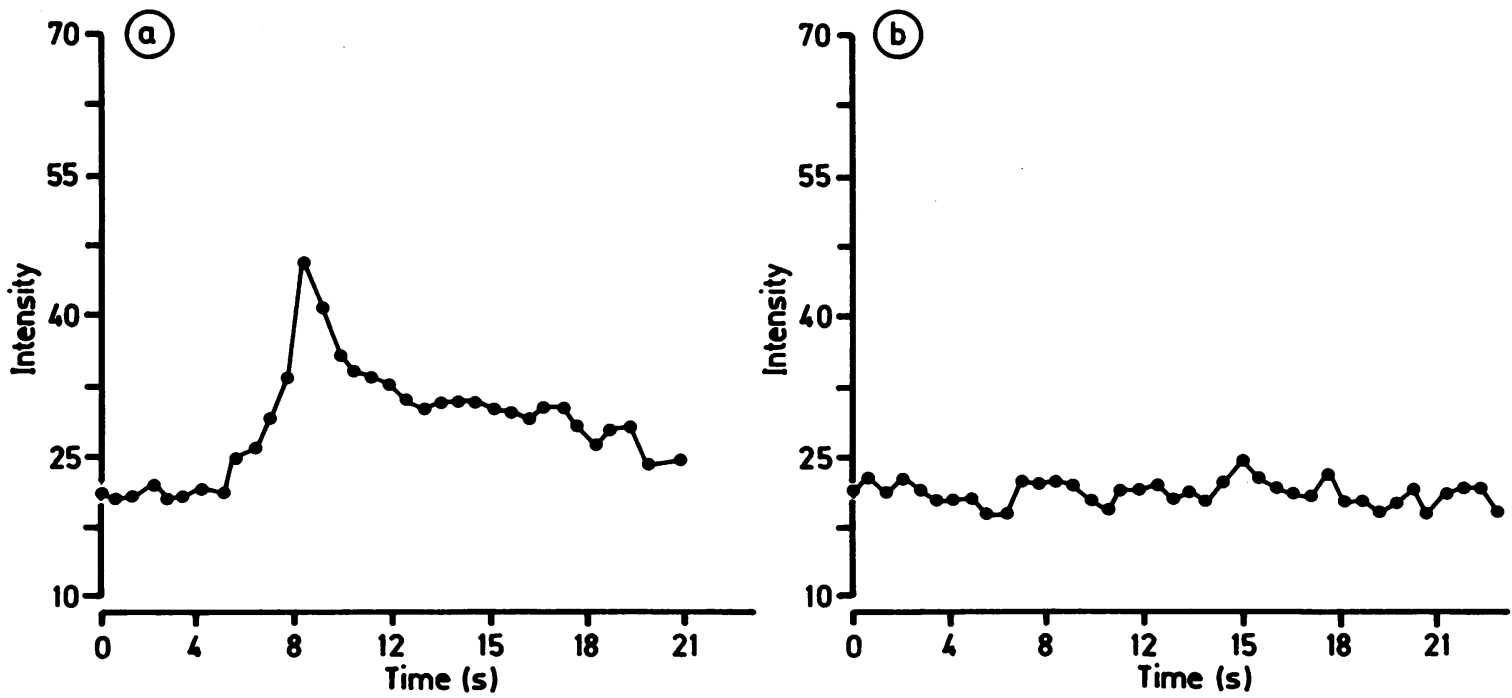

Fig 2 Time-intensity curves of myocardial echocontrast. (a) Sharp transient increase in lateral wall videointensity during transit of echocontrast; (b) no change in septal videointensity after echocontrast injection. Intensity is displayed in arbitrary units and time in seconds (s). 
analysis of the time-intensity curve of myocardial contrast confirmed that there was no increase in septal videointensity and a considerable transient increase in the intensity of echocontrast in the lateral wall (fig 2).

\section{Discussion}

There was a striking difference between the findings of myocardial contrast enhanced cross sectional echocardiography in both patients. Clinically and in terms of wall motion analysis they seemed to be similar: both had a history of an anteroseptal transmural myocardial infarction with ensuing apicoseptal akinesia or dyskinesia. The first patient had severe proximal double stenosis of the left anterior descending coronary artery and good contrast opacification of the septum by collaterals from the right coronary artery. The second patient had good patency of all three major epicardial coronary arteries, but he had a large perfusion defect of the whole septum and apex. The most probable explanation for this difference is that the first patient had preserved septal microcirculation and thus potential viability of the septum. The second patient had septal scar tissue without preserved microcirculation, as shown by the very poor branching of the left anterior descending coronary artery.

In our experience and that of others ${ }^{6}$ the right coronary artery supplies the posterior aspect of the interventricular septum. This segment is not visualised in apical views and is best seen from short axis cross sections. This type of examination was not performed in the present study.

Septal wall motion is altered in patients with left bundle branch block but it is difficult to differentiate between septal scar tissue and viable septum that is dyskinetic because of the left bundle branch block. Our first patient is an example of a case of left bundle block in which myocardial contrast enhanced cross sectional echocardiography could be used to assess septal viability.
We conclude that these two cases demonstrate the potential value of myocardial contrast enhanced cross sectional echocardiography for the assessment of myocardial and collateral blood flow. Contrast enhanced echocardiography may be a useful supplement to coronary arteriography for the assessment of regional myocardial perfusion.

This study was supported by grant 85060 of the Nederlandse Hart Stichting's Gravenhage.

$P W$ is a cardiac research exchange fellow from Medical Department II, Charles University, Prague, Czechoslovakia.

\section{References}

1 Sakamaki T, Tei C, Meerbaum S, et al. Verification of myocardial contrast two-dimensional echocardiographic assessment of perfusion defects in ischemic myocardium. $\mathrm{J} \mathrm{Am}$ Coll Cardiol 1984;3:34-8.

2 Kemper AJ, O'Boyle JE, Cohen CA, Taylor A, Parisi AF. Hydrogen peroxide contrast echocardiography: quantification in vivo of myocardial risk area during coronary occlusion and of the necrotic area, remaining after myocardial reperfusion. Circulation 1984; 70:309-17.

3 Santoso T, Roelandt J, Mansyoer H, Abdurahman N, Meltzer RS, Hugenholtz PG. Myocardial perfusion imaging in humans by contrast echocardiography using polygelin colloid solution. J Am Coll Cardiol 1985;6:612-20.

4 Lang RM, Feinstein SB, Feldman T, Neuman A, Chua KG, Borow KM. Contrast echocardiography for evaluation of myocardial perfusion: effects of coronary angioplasty. J Am Coll Cardiol 1986;8:232-5.

5 Feinstein SB, Ten Cate JF, Zwehl W, et al. Twodimensional contrast echocardiography. I. In vitro development and quantitative analysis of echo contrast agents. J Am Coll Cardiol 1984;3:14-20.

6 Feinstein SB, Lang RM, Neumann A, et al. Contrast echocardiography during cardiac catheterization in humans [Abstract]. J Am Coll Cardiol 1987;9:113A. 